\title{
Symposium review: The Mozzarella/pasta filata years: A tribute to David M. Barbano*
}

\author{
Paul S. Kindstedt $†$ \\ Department of Nutrition and Food Sciences, University of Vermont, Burlington 05405
}

\begin{abstract}
In the decades that followed the end of World War II, Mozzarella cheesemaking in the United States grew steadily as the pizza restaurant established an everexpanding footprint across America and beyond. By the 1980s, Mozzarella cheesemaking had attained unprecedented scales of production, yet even as new cheese plants were coming on line across the country and production capacities were reaching extraordinary levels, the scientific and technological knowledge base needed to standardize production schedules, control product quality, and maximize cheese yields and efficiency lagged far behind industry needs. It was within this historical context that David Barbano turned his systematic and meticulous research program toward the needs of the Mozzarella cheese industry during the 1980s. By the early 1990s, Barbano was leading a team of graduate students, post-docs, technical staff, and collaborators in a systematic evaluation of every step in the Mozzarella cheesemaking process. The end product of these studies was nothing less than the transformation of what had been (to a large degree) a poorly understood "black box" process into a precisely controlled make procedure that lent itself to precision tailoring of cheese functionality, tight control over manufacturing schedules and efficiency, and maximization of cheese yields. Barbano's international collaborators included research scientists from Italy, where Mozzarella originated. Working with them, Barbano led a systematic evaluation of the scientific and technological aspects of Ragusano cheese, a traditional Protected Designation of Origin pasta filata cheese from Sicily. In the process, Barbano's team demonstrated a new approach to traditional artisanal practices that merged both the art and science of cheesemaking, in effect combining the best of both worlds, toward the goal of sustaining traditional cheesemakers and the working landscapes
\end{abstract}

\footnotetext{
Received June 11, 2019.

Accepted July 2, 2019.

*Presented as part of the David M. Barbano Recognition Symposium at the ADSA Annual Meeting, Cincinnati, Ohio, June 2019.

†Corresponding author: paul.kindstedt@uvm.edu
}

that they support. Throughout all of these studies, Barbano's research led to innovations in cheesemaking technology (such as improved salting methods, preacidification treatments, and strategies to improve low-fat Mozzarella functionality) that have revolutionized the Mozzarella industry worldwide.

Key words: Mozzarella, pasta filata, cheese

\section{INTRODUCTION}

In 1970, per capita consumption of Mozzarella cheese in the United States stood at $0.54 \mathrm{~kg}$. By 2017, US per capita consumption had increased nearly 10 -fold to 5.25 $\mathrm{kg}$, and annual production of Mozzarella cheese ranked number one in the United States, totaling around 1.89 billion kilograms. During this same period, substantial increases in Mozzarella production and consumption occurred globally, and this remarkable worldwide growth in demand for this one particular cheese is arguably unprecedented in the 10,000-year history of cheesemaking. Driving this growth, more than any other factor, was the rise in popularity of pizza. Never before has a single cheese variety risen so quickly to prominence and precipitated such rapid scale-up and technological transformation of the cheese manufacturing industry as occurred with Mozzarella in the late 20th century.

During the same period, Cheddar cheese experienced impressive gains in production and consumption, and the scale and technological sophistication of Cheddar cheese plants also increased dramatically. However, by this time, Cheddar cheese had been systematically studied and scientifically characterized by researchers in America, Canada, England, New Zealand, Australia, and beyond for nearly a century, and considerable scientific and technological underpinnings were already in place to support the growth of the Cheddar cheese industry. The same was not true for Mozzarella. Indeed, the level of understanding of Mozzarella science and technology leading to the early growth of the industry during the 1960s and 1970s was remarkably limited. This was the context within which David M. Barbano began a sustained program of research on Mozzarella, a pasta filata or stretched curd cheese, during the early 1980s that lasted for 2 decades. Barbano's ground- 
breaking work helped to establish the knowledge base that enabled the science and technology of Mozzarella cheesemaking to catch up with the breakneck growth that the industry had been experiencing. Barbano's research also transformed and strengthened traditional artisanal production of pasta filata cheese in Italy and beyond.

\section{THE RISE OF ITALIAN CHEESEMAKING IN AMERICA: 1900-1950}

At the start of the 20th century, waves of immigrants from southern Italy settled in the United States and formed sizable ethnic communities in New York, Boston, Philadelphia, and other major east coast cities, as well as in San Francisco and surrounding regions of California and, to a lesser extent, the Midwest. Consequently, by the early 1920s, America had become a lucrative export market for cheeses produced in Italy, as the population of Italian immigrants and their descendants grew ever larger and craved the foods of their former homeland (Durand, 1948). Imported cheeses from Italy, which totaled around 18 million kilograms annually during the 1920s, included varieties that were able to withstand the rigors of transportation to America by sea and thus limited to hard and semi-hard types, such as Parmesan, Romano, Provolone, and Caciocavello. These durable aged Italian cheese imports quickly carved out sizable markets in the ethnic Italian communities of America, especially along the east coast. However, Mozzarella cheese, the soft fresh pasta filata cheese made in southern Italy, was not among the imports to America because of its short shelf life (Chen, 2003). By the end of the 1920s, domestic Italian cheese producers had sprung up in New York State, California, and Wisconsin, founded by Italian immigrants who had gained their cheesemaking experience back in the "old country," and who reproduced copied versions to challenge the imported cheeses from Italy (Ferris and Palmiter, 1987).

Production of hard and semi-hard Italian cheeses in America increased rapidly during the 1930s and 1940s, especially in Wisconsin and the Upper Peninsula of Michigan. By mid-century, Italian cheeses as a category ranked second only to Cheddar in US cheese production. Hard and semi-hard aged types, such as Asiago, Caciocavello, Parmesan, Provolone, and cow milk Romano dominated the Italian cheese category, and Wisconsin became the largest producer of these cheeses. The markets for Italian cheeses extended coast to coast, but the large ethnic Italian communities of the east coast still constituted the largest single market by far (Durand, 1948).
The situation for soft fresh Italian cheeses such as Mozzarella (and Ricotta) was somewhat different. Although immigrant cheesemakers from Italy set up small factories to produce Mozzarella as early as the 1920s, Mozzarella production remained largely localized geographically to regions close to metropolitan centers where large ethnic Italian communities were concentrated. In traditional Mozzarella cheesemaking, newly made partially acidified cheese curd was produced from raw milk, without the use of starter culture. The curd was placed in cloth bags, iced and cooled overnight, and then typically transported to the place of retail sale in city, where the curd was allowed to warm and further acidify until ready for stretching in hot $\left(160-180^{\circ} \mathrm{F}\right)$ water. Stretching and molding were performed by hand to order, as was the custom in southern Italy (Kosikowsky, 1951; Ferris and Palmiter, 1987). The very brief shelf life of traditional Mozzarella meant that Mozzarella factories had to be located very close to the metropolitan centers where the ethnic Italian communities were concentrated. This essentially ruled out large increases in Mozzarella production in the Midwest during the first half of the 20th century due to the great distances to the large east coast markets. Therefore, Midwest producers of Italian cheeses concentrated on hard durable types, which included lower moisture pasta filata cheeses, such as Provolone which grew rapidly in both production and technological sophistication (Durand, 1948).

In contrast, production of Mozzarella in the eastern US experienced few technological advances before World War II; indeed, until 1950, much Mozzarella was still produced in the old way from raw milk without starter cultures in small factories near the large east coast urban centers. The physically grueling step of stretching and molding the cheese was still completed by hand. Kosikowsky (1951), who conducted some of the earliest research on starter cultures for the traditional Mozzarella industry in response to the public health authorities requiring pasteurization of Mozzarella cheese milk, noted the lack of knowledge and pressing need for fundamental research on Mozzarella. Around the same time, Midwest producers of the hard aged pasta filata cheeses such as Provolone began to experiment with cheesemaking modifications to produce a slightly higher moisture version that could be used in the unripened state as a substitute for traditional Mozzarella (Reinbold, 1963; Ferris and Palmiter, 1987; Chen, 2003). These efforts led to the development of "pizza cheese," a lower-moisture, firmer-bodied, longershelf-life pasta filata cheese that shared many commonalities with traditional Mozzarella. Federal Standards of Identity were enacted in 1966 to differentiate the 
traditional higher moisture Mozzarella from the lower moisture "pizza cheese" version (Christensen, 1966). Low moisture (LM) Mozzarella, with its firmer body and longer shelf life, quickly challenged traditional Mozzarella for supremacy as the premier ingredient of pizza, at a time when pizza was beginning to transform American food culture.

\section{PIZZA AND THE TRANSFORMATION OF TRADITIONAL MOZZARELLA}

Until World War II, pizza in America had largely remained an ethnic food that was rarely enjoyed outside of ethnic Italian communities in metropolitan areas. After the war, however, America changed dramatically, becoming much more mobile as automobile ownership became ubiquitous, the highway system expanded, and population centers increasingly spread out from city centers to surrounding suburbs, which were springing up all across the nation during the 1950s and 1960s. America was also becoming much more prosperous as the post-war economy expanded at an unprecedented rate. American food culture likewise changed dramatically, becoming more diverse, multi-ethnic, adventurous, and convenience-oriented. Among the repercussions of these changes was the diffusion of the Italian restaurant-and pizza - out of "little Italy" in the metropolitan areas to the surrounding suburbs, creating a much wider market for Italian cuisine than ever before. Mozzarella, the quintessential pizza topping, benefited from the growth of pizza, and production and consumption of Mozzarella began to rise steadily during the 1960s (Spurgeon, 1985).

By 1970, per capita consumption of Mozzarella cheese in the United States had reached $0.54 \mathrm{~kg}$, triple the level of $0.18 \mathrm{~kg}$ in 1960. Over the next decade, consumption would again nearly triple to $1.37 \mathrm{~kg}$, as restaurants dedicated solely to pizza expanded and proliferated through the creation of local, regional, and eventually national and international franchise restaurant chains. Large institutional buyers of LM Mozzarella cheese placed a premium on product consistency at every restaurant, which meant that cheese manufacturers that supplied franchise chains had to produce cheese at increasing scales of production with consistent shredding and melting characteristics tailored to precise buyer specifications and distributed through increasingly complex systems (Spurgeon, 1985). It also meant that large institutional buyers wielded a great advantage over their suppliers to negotiate price; therefore, maximizing cheese yield and optimizing the economics of Mozzarella production became essential as price competition became increasingly intense (Barbano, 1984).
During the 1950s through the 1970s, land-grant university researchers, most notably at Cornell University, the University of Wisconsin, and the University of Vermont, began to expand the scientific and technological underpinnings to support the LM Mozzarella industry. However, by the 1980s, the scientific knowledge base had not kept pace with the technical needs of the frantically growing Mozzarella industry, even as per capita consumption of Mozzarella reached $3.13 \mathrm{~kg}$. The industry urgently needed a better understanding of the functional characteristics of Mozzarella cheese and the means to tailor them precisely and consistently to satisfy customer requirements for specific applications, as well as better control over the economic aspects of cheesemaking (Barbano, 1984; Spurgeon, 1985; Pilcher and Kindstedt, 1990). It was during this time of need that David M. Barbano embarked on a research program that aimed to support Mozzarella cheesemakers.

\section{BARBANO AND THE TRANSFORMATION OF PIZZA CHEESE}

During the early 1980s, Barbano had been working on innovative methods to measure, predict, and optimize the yield and economics of Cheddar cheese, which eventually led to a series of articles published in the Journal of Dairy Science. Around the same time, Barbano became interested in using similar approaches to study the yield and economics of Mozzarella cheese. In 1983, he presented a paper on Mozzarella cheese yield at the Marschall Invitational Italian Cheese Seminar (Barbano, 1983). The Marschall Seminar was an annual conference and trade show for industry, which for 3 decades served as one of the premier forums for presenting new advances in science and technology to the Italian cheese industry. Barbano returned to the Marschall Seminar each year from 1984 through 1988 to present additional papers on topics related to Mozzarella yield and economics (Barbano, 1984, 1985, 1986, 1987; Barbano et al., 1988); indeed, for the next decade, Barbano and his Mozzarella research team members became a regular fixture of the Marschall Italian Cheese Seminar.

The various papers that Barbano published on Mozzarella yield and economics in the proceedings of the Marschall Seminar Series formed a body of work that complemented his corresponding papers on Cheddar cheese yield in the Journal of Dairy Science. Barbano essentially used his Cheddar cheese research program as a launch pad to study Mozzarella cheese. He was able to leverage the 2 research avenues with great effectiveness because the manufacturing procedures for Cheddar and LM Mozzarella are remarkably similar throughout most of the process. Consequently, the ap- 
proaches and models that he developed for Cheddar yield could, with the help of some additional studies, be readily modified to describe Mozzarella yield. Barbano's rapid progress in the Mozzarella field and his rapid transfer of the findings to the Mozzarella industry through the Marschall Italian Cheese Seminar series helped to transform the economics of Mozzarella cheesemaking during this period of production increases at Mozzarella plants across the country (Barbano, 1996).

However, it was not just knowledge about how to measure, predict, and optimize cheese yield that Mozzarella manufacturers needed during the 1980s. Cheesemakers also lacked a fundamental understanding of how each step in the cheesemaking process affects the quality characteristics of the final cheese. Consequently, they lacked the knowledge needed to optimize each step in order to produce cheeses that were consistent in quality from vat to vat and from day to day, and that could be tailored to the expectations of different customers who wanted different functional attributes. Particularly troublesome were the large changes that characteristically occur in LM Mozzarella functional characteristics during storage, making it difficult for manufacturers to ensure that their cheeses had optimum functional characteristics at the time of end use. During the 1980s, the factors that drive the process of functionality change in Mozzarella cheese were poorly understood, adding to the dilemma of gaining control over product quality.

Therefore, in 1989, Barbano began the first in a series of research projects aimed at developing a comprehensive understanding of how each step in the LM Mozzarella cheesemaking processes influences the final cheese. This was to be accomplished by systematically changing key conditions at each manufacturing step, and then determining the effects on chemical composition, proteolytic, and functional characteristics, and general aging behavior of the resulting cheeses. To that end, Barbano chose a series of experimental variables that cheesemakers had to deal with every day, relating to the milk (Yun et al., 1998), the starter culture (Hong et al., 1998a,b; Yun et al., 1995a), the coagulant (Yun et al., 1993c,d; Kindstedt, et al., 1995b), cooking temperature (Yun et al., 1993e), acidities at draining (Yun et al., 1994, 1995b) and milling (Yun et al., 1993a,b), and stretching conditions (Barbano et al., 1994b; Kindstedt et al., 1995a; Renda et al., 1997).

Before embarking on this ambitious plan, however, Barbano was concerned about the last step in cheesemaking, brine salting, which results in characteristically large gradients of composition and functional characteristics within the final cheese, thereby making it difficult to obtain representative samples for testing and complicating the interpretation of experimental results. Therefore, to prevent within-cheese compositional variation, Barbano's team conducted a series of preliminary studies to develop a method to add salt to Mozzarella curd before the stretching step. This resulted in a pilot-scale cheesemaking protocol referred to as the "milled curd no-brine" procedure (Yun et al., 1993a). Further refinements to the no-brine cheesemaking protocol to increase the moisture content of the final cheese eventually led to a "stirred curd no-brine" method for Mozzarella cheese (Barbano et al., 1994a). During these studies, essential information was gained about changes in the rheology of presalted curd during stretching versus that of unsalted curd, the former becoming much firmer and requiring much more mechanical work during stretching, which necessitated changes in the operating conditions of the stretcher to process the curd. The curd also lost much more moisture during presalting and stretching, resulting in much lower moisture contents in the resulting no-brine cheese unless the cheesemaking steps were modified to produce a much higher moisture curd at the time of salting to offset losses during presalting and stretching. Reduction of total manufacturing time by increasing the acidification rate proved to be a very effective means to increase cheese moisture content and also resulted in lower calcium content in the curd, which contributed to a softer, more workable curd in the stretcher.

Although the no-brine cheesemaking system was developed for Barbano's pilot-plant research studies, the approach had potential commercial applications. On an industrial cheesemaking scale, brining requires enormous brine tanks that are a bottleneck for an otherwise continuous cheesemaking process. Furthermore, brines are corrosive, they are a constant risk factor for microbial contamination, and they pose environmental problems when brine eventually needs to be disposed of. The no-brine process served as an important step forward toward replacement of brining in commercial Mozzarella cheesemaking, and it was the first of several spin-off technologies from Barbano's Mozzarella program that positively affected the industry.

With the no-brine pilot-scale cheesemaking procedure in place, Barbano's team methodically deconstructed the LM Mozzarella cheese-make procedure. Of the various steps examined, the stretching step turned out to be particularly important in terms of both yield and quality. In many ways, the stretcher at this time was the proverbial "black box." In the Mozzarella factory, newly made curd was fed into the stretcher continuously, where it entered a reservoir of hot water that would increase the curd temperature and transform its rheology into a molten plasticized consistency. The hot plastic curd was then worked by a set of counter-rotating augers, or screws, along an inclined heated chamber, 
and after a residence time of several minutes, the curd exited the stretcher as a hot continuous plastic ribbon of cheese, which then went into a hopper that fed into a molding machine. Getting the curd successfully though the stretcher was imperative, and cheesemakers would do whatever was necessary to keep this unit operation running continuously. This usually meant modulating one or both key parameters of the stretcher: the speed of the augers (screw speed), which determined the transit time of the curd through the stretcher, and the stretching temperature profile, which was determined by the temperature of the stretching water and that of the inclined chamber, along with the total transit time of the curd through the stretcher. During the 1970s and 1980s, there was very little understanding of how these parameters affected the final cheese.

To ascertain what happens during stretching, Barbano's team conducted 3 cheesemaking trials designed to evaluate the effects of (1) stretching temperature, with screw speed and other conditions held constant; (2) screw speed when stretching is performed at the low end of the stretching temperature range and all other conditions are held constant; and (3) screw speed when stretching is performed at the high end of the stretching temperature range and all other conditions are held constant.

Results from these trials can be summarized as two major "take home" lessons. First, operating the cookerstretcher at the low end of the possible temperature range $\left(\sim 51-55^{\circ} \mathrm{C}\right)$ greatly increased the risk of yield losses during stretching; faster screw speeds at these low temperatures caused much greater fat and moisture losses from the curd during stretching (Barbano et al., 1994b; Renda et al., 1997). The practical implication is that Mozzarella curd entering the stretcher must remain in the hot water reservoir long enough to heat up and acquire a plastic consistency before the augers begin stretching and texturizing the curd. If the curd temperature is too low and its consistency not yet plastic-like, the screws will rip the curd apart and squeeze out fat and water, which are lost to the stretching water. The result is both loss of cheese yield and change in cheese composition (lower moisture and fat contents), which may have implications for functional characteristics. Thus stretching temperature and screw speed need to be finely balanced with one another and with the rheological properties of the curd entering the stretcher.

The second lesson from this series of experiments pertains to the high end of the stretching temperature range $\left(60-66^{\circ} \mathrm{C}\right)$. The concerns at a high stretching temperature were less about cheese yield losses and cheese compositional changes, and more about changes in microbiology, proteolysis, functionality, and aging behavior caused by the time-temperature treatment to which the curd was subjected. For example, stretching temperature had significant effects on titratable acidity, $\mathrm{pH}$, and trichloroacetic acid (TCA)-soluble nitrogen values of the cheese during aging. Specifically, titratable acidity values and TCA-soluble nitrogen levels were much lower and $\mathrm{pH}$ values were much higher throughout aging for cheese stretched at $66^{\circ} \mathrm{C}$ than for that stretched at lower temperatures, which strongly suggested that the starter culture bacteria were either killed by the heat treatment or shocked into a metabolically inert state. Levels of $\mathrm{pH}$ 4.6-soluble nitrogen were also much lower in cheese stretched at $66^{\circ} \mathrm{C}$, indicating much lower coagulant (i.e., chymosin) activity. Thus, both the starter culture bacteria and the residual coagulant were significantly affected when stretching temperatures increased to $66^{\circ} \mathrm{C}$. Furthermore, cheeses stretched at $66^{\circ} \mathrm{C}$ showed much slower decreases in hardness and apparent viscosity during storage at $4^{\circ} \mathrm{C}$, indicating a substantial alteration of functional characteristics (Kindstedt et al., 1995a). The bottom line is that the microbiological, proteolytic, and functional profiles of cheeses during aging were altered substantially when curd temperature was increased to $66^{\circ} \mathrm{C}$ during stretching. The practical implication is that stretching temperature can have a large effect on cheese functional characteristics and aging when stretching is conducted at the high end of the temperature range.

In addition, the water-holding capacity of cheese decreased dramatically when the stretching temperature increased to around $66^{\circ} \mathrm{C}$. As Barbano's trials progressed, it became clear that high stretching temperature also induces physico-chemical changes that dramatically alter the relationships between casein and water and between casein and calcium in the cheese, which, in turn, influenced cheese functional characteristics (Kindstedt et al., 1995a). Ultimately, this work led to the conclusion that there are 2 drivers of functional changes in LM Mozzarella cheese during aging - proteolytic and physico-chemical changes - which act concurrently but independently of one another.

Eventually, Barbano turned his attention toward solving the problems of low-fat and fat-free Mozzarella cheese. Such cheese was notorious for not melting and flowing when baked in an oven, for scorching during baking, for becoming tough and chewy during cooling after baking, and for lacking whiteness and displaying a somewhat transparent appearance; thus, the challenges were multi-faceted. Through a series of experiments, Barbano and his team identified 3 fundamental problems that needed to be solved and then developed solutions for those problems. The first problem was related to the lack of free oil release from very low fat and nonfat Mozzarella during baking. Without free oil 
release, Mozzarella dries out excessively, fails to flow, and scorches during baking (Rudan et al., 1999). These problems were alleviated by spraying a thin film of food-grade lipid onto the cheese before baking, which created a hydrophobic surface barrier that prevented drying, case hardening, and scorching, without contributing appreciably to the fat content of the cheese (Rudan and Barbano, 1998). The second problem, that of tough, excessively chewy texture in melted low-fat and nonfat Mozzarella, was addressed using physico-chemical remedies (preacidification) to promote casein-water interactions by decreasing casein-calcium interactions (Metzger et al., 2000a,b, 2001a,b). Finally, the lack of whiteness was addressed through selective homogenization of cream, or fat substitute, before recombination with skim milk to standardize the cheese milk (Rudan et al., 1998a,b).

The result of this long series of research projects spanning more than a decade was the creation of a toolbox of approaches that industry could apply to commercial Mozzarella cheesemaking. It also generated a comprehensive set of benchmarks for how each step can influence the final cheese. Of course, Barbano's team was not the only research group investigating Mozzarella during the 1980s and 1990s. Much excellent work was conducted concurrently at Utah State University, the University of Wisconsin, Teagasc-Moorepark in Ireland, the Dairy Research Institute in New Zealand, and elsewhere during this critical time. However, Barbano's work was irreplaceable because it was comprehensive, providing benchmarks that other researchers could reference and build upon, which they did brilliantly. The result was a truly remarkable increase in scientific and technical knowledge that underpinned the Mozzarella industry during this time of amazing growth.

\section{BARBANO AND THE TRANSFORMATION OF RAGUSANO}

In the world of large-scale industrial pizza cheese manufacturing, David M. Barbano was a leading thinker and researcher. However, Barbano also profoundly influenced the world of traditional artisanal pasta filata cheesemaking. Working with Guiseppe Licitra and colleagues at CorFilac in Sicily, Barbano conducted extensive studies on the traditional artisanal make procedure for Ragusano cheese, an aged pasta filata cheese made in Sicily using traditional practices. The team of Barbano, Licitra, and colleagues at CorFilac generated a comprehensive scientific base of knowledge about the making, aging, and quality characteristics of Ragusano cheese (Licitra et al., 1998, 2000; Melilli et al., 2003a,b, 2004a,b, 2005; Carpino et al., 2004a,b). In many respects, this team did for artisanal Ragusano cheesemakers what Barbano's team had done for industrial producers of pizza cheese. In the process, Barbano helped to preserve a centuries-old way of life and the working landscape of Sicily that depends on artisanal cheesemaking.

\section{REFERENCES}

Barbano, D. M. 1983. Italian Cheese Yields. Pages 79-85 in Proc. 20th Annu. Marschall Invitational Ital. Cheese Sem., Miles Laboratories Inc., Madison, WI.

Barbano, D. M. 1984. Mozzarella cheese composition, yield, and how composition control influences profitability. Pages 1-13 in Proc. 21st Annu. Marschall Invitational Ital. Cheese Sem., Miles Laboratories Inc., Madison, WI.

Barbano, D. M. 1985. Rapid milk casein determination by infrared analysis. Pages 42-48 in Proc. 22nd Annu. Marschall Invitational Ital. Cheese Sem., Miles Laboratories Inc., Madison, WI.

Barbano, D. M. 1986. Impact of seasonal variation in milk composition on Mozzarella cheese yields and composition. Pages $64-78$ in Proc. 23rd Annu. Marschall Invitational Ital. Cheese Sem., Miles Laboratories Inc., Madison, WI.

Barbano, D. M. 1987. Influence of milk somatic cell count on cheese manufacturing and cheese yield. Pages 74-80 in Proc. 24th Annu. Marschall Ital. Cheese Sem., Miles Inc., Madison, WI.

Barbano, D. M. 1996. Product yield formulae: Evaluation of plant efficiency and decision making for fortification. Pages 25-34 in Proc. Marschall Ital. Specialty Cheese Sem., Rhône-Poulenc, Madison, WI.

Barbano, D. M., J. Mesa-Dishington, and R. O. Aplin. 1988. Economics of cheese production costs. Pages 17-26 in Proc. 25th Annu. Marschall Ital. Cheese Sem., Miles Inc., Elkhart, IN.

Barbano, D. M., A. Renda, J. J. Yun, and P. S. Kindstedt. 1994b. Influence of cheese temperature and screw speed on Mozzarella cheese yield. Pages 1-6 in Proc. 31st Annu. Marschall Ital. Cheese Sem., Rhône-Poulenc, Madison, WI.

Barbano, D. M., J. J. Yun, and P. S. Kindstedt. 1994a. Mozzarella cheese making by a stirred-curd no-brine procedure. J. Dairy Sci. $77: 2687-2694$.

Carpino, S., J. Horne, C. Melilli, G. Licitra, D. M. Barbano, and P. J. Van Soest. 2004a. Contribution of native pasture to the sensory properties of Ragusano cheese. J. Dairy Sci. 87:308-315.

Carpino, S., S. Mallia, S. La Terra, C. Melilli, G. Licitra, T. E. Acree, D. M. Barbano, and P. J. Van Soest. 2004b. Composition and aroma compounds of Ragusano cheese: Native pasture and total mixed ration. J. Dairy Sci. 87:816-830.

Chen, C. 2003. Pasta filata to LMPS - The evolution of Mozzarella cheese. Dairy Pipeline 15:1, 4-7.

Christensen, V. W. 1966. Comparison of manufacturing methods for high and low moisture Mozzarella. Pages 1-7 in Proc. 3rd Annu. Marschall Invitational Ital. Cheese Sem., Marschall Dairy Laboratory Inc., Madison, WI.

Durand, L. 1948. Italian cheese production in the American dairy region. Econ. Geogr. 24:217-230.

Ferris, S., and H. Palmiter. 1987. Italian-type cheese in the U.S.A. American Producers of Italian-type Cheese Association.

Hong, Y.-H., J. J. Yun, D. M. Barbano, and P. S. Kindstedt. 1998a. Mozzarella cheese: Impact of three commercial Lactobacillus culture strains on composition, proteolysis, and functional properties. Aust. J. Dairy Technol. 53:163-169.

Hong, Y.-H., J. J. Yun, D. M. Barbano, and P. S. Kindstedt. 1998b. Impact of three commercial Lactobacillus culture strains on Mozzarella cheese yield. Aust. J. Dairy Technol. 53:170-174.

Kindstedt, P. S., M. R. Guo, W. H. Viotto, J. J. Yun, and D. M. Barbano. 1995a. Effect of screw speed and residence time at high stretching temperature on composition, proteolysis, functional properties and the water phase of Mozzarella cheese. Pages 56-72 in Proc. 32nd Annu. Marschall Ital. Cheese Sem., Rhône-Poulenc. Madison, WI. 
Kindstedt, P. S., J. J. Yun, D. M. Barbano, and K. L. Larose. 1995b. Mozzarella cheese - Impact of coagulant level on chemical composition, proteolysis and functional characteristics. J. Dairy Sci. 78:2591-2597.

Kosikowsky, F. V. 1951. The manufacture of Mozzarrelle cheese from pasteurized milk. J. Dairy Sci. 36:641-648.

Licitra, G., P. Campo, M. Manenti, G. Portelli, S. Scuderi, S. Carpino, and D. M. Barbano. 2000. Composition of Ragusano cheese during aging. J. Dairy Sci. 83:404-411.

Licitra, G., G. Portelli, P. Campo, G. Logombardo, G. Farina, S. Carpino, and D. M. Barbano. 1998. Technology to produce Ragusano cheese: A survey. J. Dairy Sci. 81:3342-3349.

Melilli, C., D. M. Barbano, M. Caccamo, M. A. Calvo, G. Schembari, and G. Licitra. 2004b. Influence of brine concentration, brine temperature, and presalting on early gas defects in raw milk pasta filata cheese. J. Dairy Sci. 87:3648-3657.

Melilli, C., D. M. Barbano, G. Licitra, G. Portelli, G. Di Rosa, and S. Carpino. 2003b. Influence of the temperature of the salt brine on salt uptake by Ragusano cheese. J. Dairy Sci. 86:2799-2812.

Melilli, C., D. M. Barbano, G. Licitra, G. Tumino, G. Farina, and S. Carpino. 2003a. Influence of presalting and brine concentration on salt uptake by Ragusano cheese. J. Dairy Sci. 86:1083-1100.

Melilli, C., D. M. Barbano, M. Manenti, J. M. Lynch, S. Carpino, and G. Licitra. 2004a. Lipolysis and proteolysis in Ragusano cheese during brine salting at different temperatures. J. Dairy Sci. 87:2359-2374.

Melilli, C., D. Carcò, D. M. Barbano, G. Tumino, S. Carpino, and G. Licitra. 2005. Composition, microstructure, and surface barrier layer development during brine salting. J. Dairy Sci. 88:2329-2340.

Metzger, L. E., D. M. Barbano, and P. S. Kindstedt. 2001b. Effect of milk preacidification on low fat Mozzarella cheese: 3. Post-melt chewiness and whiteness. J. Dairy Sci. 84:1357-1366.

Metzger, L. E., D. M. Barbano, P. S. Kindstedt, and M. R. Guo. 2001a. Effect of milk preacidification on low fat Mozzarella cheese: 2. Chemical and functional properties during storage. J. Dairy Sci. 84:1348-1356

Metzger, L. E., D. M. Barbano, M. A. Rudan, and P. S. Kindstedt. 2000b. Effect of milk preacidification on low fat Mozzarella cheese: 1. Composition and yield. J. Dairy Sci. 83:648-658.

Metzger, L. E., D. M. Barbano, M. A. Rudan, P. S. Kindstedt, and M. R. Guo. 2000a. Whiteness change during heating and cooling of Mozzarella cheese. J. Dairy Sci. 83:1-10.

Pilcher, S. W., and P. S. Kindstedt. 1990. Survey of Mozzarella cheese quality at restaurant end use. J. Dairy Sci. 73:1644-1647.

Reinbold, G. W. 1963. Italian Cheese Varieties. Pfizer Cheese Monographs, Vol. 1, Chas. Pfizer \& Co., NY.

Renda, A., J. J. Yun, D. M. Barbano, P. S. Kindstedt, and S. Mulvaney. 1997. Influence of screw speed of the mixer at low temperature on characteristics of Mozzarella cheese. J. Dairy Sci. 80:1901-1907.
Rudan, M. A., and D. M. Barbano. 1998. A model of Mozzarella cheese melting and browning during pizza baking. J. Dairy Sci. 81:2312-2319

Rudan, M. A., D. M. Barbano, and P. S. Kindstedt. 1998a. Effect of fat particle size (homogenization) on low fat Mozzarella cheese chemical composition, proteolysis, functionality, and appearance. J. Dairy Sci. 81:2065-2076.

Rudan, M. A., D. M. Barbano, and P. S. Kindstedt. 1998b. Effect of fat replacer (Salatrim) on chemical composition, proteolysis, functionality, appearance, and yield of reduced fat Mozzarella cheese. J. Dairy Sci. 81:2077-2088.

Rudan, M. A., D. M. Barbano, J. J. Yun, and P. S. Kindstedt. 1999. Mozzarella cheese: Effect of fat reduction on chemical composition, proteolysis, functionality, and Yield. J. Dairy Sci. 82:661-672.

Spurgeon, M. L. 1985. Italian cheese: Number two and still not satisfied. Pages 24-38 in Proc. 22nd Annu. Marschall Invitational Ital Cheese Sem., Miles Laboratories Inc., Madison, WI.

Yun, J. J., D. M. Barbano, L. J. Kiely, and P. S. Kindstedt. 1993b. Mozzarella cheese: Impact of milling $\mathrm{pH}$ on functional properties. J. Dairy Sci. 76:3639-3647.

Yun, J. J., D. M. Barbano, L. J. Kiely, and P. S. Kindstedt. 1995a Mozzarella cheese: Impact of rod:coccus ratio on composition, proteolysis and functional properties. J. Dairy Sci. 78:751-760.

Yun, J. J., D. M. Barbano, and P. S. Kindstedt. 1993a. Mozzarella cheese: Impact of milling $\mathrm{pH}$ on chemical composition and proteolysis. J. Dairy Sci. 76:3629-3638.

Yun, J. J., D. M. Barbano, and P. S. Kindstedt. 1993c. Mozzarella cheese: Impact of coagulant type on chemical composition and proteolysis. J. Dairy Sci. 76:3648-3656.

Yun, J. J., D. M. Barbano, K. L. Larose, and P. S. Kindstedt. 1998. Mozzarella cheese: Impact of nonfat dry milk fortification on composition, proteolysis and functional properties. J. Dairy Sci $81: 1-8$.

Yun, J. J., Y. L. Hsieh, D. M. Barbano, and P. S. Kindstedt. 1994 Draw $\mathrm{pH}$ and storage affect rheological properties of cheese. J. Food Sci. 59:1302-1304.

Yun, J. J., L. J. Kiely, D. M. Barbano, and P. S. Kindstedt. 1993d. Mozzarella cheese: Impact of coagulant type on functional properties. J. Dairy Sci. 76:3657-3663.

Yun, J. J., L. J. Kiely, D. M. Barbano, and P. S. Kindstedt. 1993e. Mozzarella cheese: Impact of cooking temperature on chemical composition, proteolysis and functional properties. J. Dairy Sci 76:3664-3673

Yun, J. J., L. J. Kiely, D. M. Barbano, and P. S. Kindstedt. 1995b. Mozzarella cheese: Impact of whey $\mathrm{pH}$ at draining on chemical composition, proteolysis and functional properties. J. Dairy Sci. $78: 1-7$. 